\title{
Erratum
}

\section{Disilene, silysilyene and their cations}

\author{
K. Somasundram, R. D. Amos, N. C. Handy
}

Theor Chim Acta (1986) 70: 393-406

We have found that one of the more interesting features of the $\mathrm{Si}_{2} \mathrm{H}_{4}$ structure is quoted incorrectly, namely the rocking angle $\alpha$, defined as the angle between the $\mathrm{HSiH}$ bisector and the $\mathrm{Si}-\mathrm{Si}$ axis. The angles actually given corresponded to a different way of defining the $\mathrm{H}$ positions, in terms of torsions about the $\mathrm{Si}-\mathrm{Si}$ bond. To clarify matters the geometries are collected in the following table. Basis sets and wavefunctions are defined in the original paper.

\begin{tabular}{llllr}
\hline & $\mathrm{R}_{\mathrm{Si}-\mathrm{Si}}(\AA)$ & $\mathrm{R}_{\mathrm{Si}-\mathrm{H}}(\AA)$ & $\mathrm{HSiH}\left(^{\circ}\right)$ & $\alpha\left(^{\circ}\right)$ \\
\hline $\mathrm{SCF} / \mathrm{DZ}+2 \mathrm{P}$ & 2.121 & 1.467 & 115.0 & 0 \\
$\mathrm{MP} 2 / \mathrm{DZ}+2 \mathrm{P}$ & 2.164 & 1.472 & 113.1 & 27 \\
$\mathrm{CISD} / \mathrm{DZ}+\mathrm{P}$ & 2.160 & 1.482 & 112.6 & 28 \\
$\mathrm{MRCISD} / \mathrm{DZ}+\mathrm{P}$ & 2.191 & 1.484 & 111.0 & 33 \\
\hline
\end{tabular}

The authors thank Dr. H. Teramae (Tokyo) for drawing this to their attention. 